\title{
Ciudad: ¿máscara civilizatoria?
}

José Miguel Segura-Gutiérrez ${ }^{*}$

Magíster (c) en Desarrollo Educativo y Social. Profesor catedrático, Universidad Cooperativa de Colombia, Villavicencio, Colombia.

Correo electrónico:

jose.segurag@campusucc.edu.co

Recibido: 13 de febrero del 2015

Aprobado: 30 de abril del 2015

Cómo citar este artículo: Segura-Gutiérrez, J. M. (2015). Ciudad: ¿máscara civilizatoria? Cooperativismo \& Desarrollo, 23(106),

67-73. doi: http://dx.doi.org/10.16925/ co.v23i106.1126

\section{Resumen}

Propósito: el artículo reflexiona en torno a la forma en que la ciudad, como expresión inacabada del proceso civilizatorio, al menos en Occidente, ha favorecido no solo la institucionalización de formas socioculturales, políticas y económicas para beneficio de la humanidad, sino que, a su turno, también ha provocado su malestar; tanto por el carácter egoísta que habita en los seres humanos, como por la búsqueda incesante de mejores condiciones de vida. Descripción: se muestra, desde la posición del ciudadano-persona, su fragilidad frente a ciertas formas de administración de la vida humana, que se emplazan desde espacios institucionales para aludir al sujeto y revelar de esa forma la compleja y problemática realidad social, subjetiva y cultural de aquellos que la habitan. Punto de vista: desde la ciudad como espacio social es posible advertir las tensiones entre los diferentes individuos que la habitan, frente a las demarcaciones socioespaciales, de tiempo y consumo. Conclusiones: la vida humana que se desarrolla en la ciudad no es más que la teatralización de un proceso civilizatorio que, en su momento, estuvo colmado de buenas intenciones. La experiencia de vivir en la ciudad no solo es racional y económica, sino también sensorial y muy emotiva.

Palabras clave: ciudad, civilización, mercado, procesos de vida. 


\title{
City: Civilizing Mask?
}

\begin{abstract}
Purpose: The article is a reflection about the way in which the city, as an unfinished expression of the civilizing process, at least in the West, has favored not only the institutionalization of sociocultural, political and economic forms for the benefit of humanity, but has also caused distress, both because of the selfish nature of human beings and their incessant search for better living conditions. Description: From the position of the citizen-person, it shows the fragility with respect to certain forms of administration of human life, that are used to subjectivize people and thereby reveal the complex and problematic social, subjective and cultural reality of the inhabitants. Point of view: It is from the city as a social space that it is possible to detect the tensions among the different individuals who inhabit it, with respect to socio-spatial demarcations of time and consumption. Conclusions: Human life in the city is simply the dramatization of a civilizing process that, in its time, was full of good intentions. The experience of living in a city is not only rational and economic, but also sensorial and very emotional.
\end{abstract}

Keywords: city, civilization, market, processes of life.

\section{Cidade: máscara civilizatória?}

\section{Resumo}

Propósito: este artigo reflete sobre a forma em que a cidade, como expressão inacabada do processo civilizatório, pelo menos no Ocidente, tem favorecido não somente a institucionalização de formas socioculturais, políticas e econômicas para benefício da humanidade, mas também que, por sua vez, tem provocado mal-estar, tanto pelo caráter egoísta que habita nos seres humanos quanto pela busca incessante de melhores condições de vida. Descrição: mostra-se, da posição do cidadão-pessoa, sua fragilidade ante certas formas de administração da vida humana, que se deslocam de espaços institucionais para subjetivar o sujeito e revelar, dessa maneira, a complexa e a problemática realidade social, subjetiva e cultural daqueles que a habitam. Ponto de vista: a partir da cidade como espaço social, pode-se advertir as tensões entre os diferentes indivíduos que a habitam ante as delimitações socioespaciais de tempo e consumo. Conclusões: a vida humana que se desenvolve na cidade não é mais que a teatralização de um processo civilizatório que, em seu momento, esteve repleto de boas intenções. A experiência de viver na cidade não somente é racional e econômica, mas também sensorial e muito emotiva.

Palavras-chave: cidade, civilização, mercado, processos de vida. 
Era una ciudad de plástico de esas que no quiero ver, de edificios cancerosos y un corazón de oropel, donde en vez de un sol, amanece un dólar, donde nadie ríe, donde nadie llora, con gentes de rostros de polyester que escuchan sin oír y miran sin ver: gente que vendió por comodidad su razón de ser y su libertad.

Rubén Blades, “Chica Plástica” (Canción).

\section{Introducción}

No cabe duda de que el término civilización tal y como hoy lo conocemos se halla cargado de cierta melancolía que nos recuerda el romanticismo encriptado de las tragedias griegas, pero a su vez, la descomunal barbarie con la que los romanos sostuvieron su espada, en el efectivo intento por sentar las bases jurídicas, políticas y administrativas del actual Estado moderno. Sin embargo, si nos preguntáramos cuál es el elemento culmen de dicho proceso civilizatorio iniciado en Grecia, y perfilado por Roma durante su ocupación a Atenas, al menos para quienes comparten una tradición occidental, diríamos que es la ciudad.

Ella se concibe:

[...] como un sistema de clases sociales, un sistema político que asegura a la vez el funcionamiento del conjunto social y la dominación de una clase, un sistema institucional de inversión, en particular, en lo referente a la cultural y a la técnica, un sistema de intercambio con el exterior (Castells, 1976, p. 19).

Lo anterior ratifica su carácter ambivalente. Es decir, su consideración como espacio de integración y lucha. Con sano criterio, la lógica de poder en las ciudades, ha venido orientándose hacia el reforzamiento de una matriz cultural-valorativa de corte heterosexual, y con pistachos de un capitalismo tardío, pero necesario para la inserción de los países no desarrollados en un mercado global. Cuestión que exige la eliminación de las particularidades del sujeto, con su posterior consecuencia en el resquebrajamiento del núcleo de la democracia (diversidad).

La ciudad en tanto escenario regular y hegemónico ha reforzado rígidamente los estereotipos de quiénes la constituyen y se ubican dentro de los límites legítimos de su complicidad, tanto que "la metrópoli moderna es, en consecuencia, un gran sistema de objetos y sujetos que se mantienen unidos por códigos individuales y sociales de no siempre fácil o inmediata interpretación y significación" (Gennari, 1998, p. 47). Tal y como se observa, desde las letras de nuestro epígrafe.

En ese sentido, preguntar por la mascarada civilizatoria que expone la ciudad implica indagar sobre tres razones concretas, que se desprenden en primer lugar, de la persona como individuo-social, en segundo término, de la presencia intervencionista del aparato estatal en las dimensiones público-privadas de los seres humanos; y finalmente, de la modelación subjetiva y corporal que realiza el mercado sobre el sujeto.

Cuestiones que se amarran a las reflexiones ya realizadas por De Sousa-Santos (2012), en su texto De la mano de Alicia, frente al proyecto sociocultural de la modernidad, o mejor aún, frente a la implantación de una forma de racionalidad cuyo origen se bifurca hacia lo estético, moral y cognoscitivo-instrumental que reside en cada individuo, y que habría de potencializarse o tratar de limitar, en razón de los intereses imperantes de la actual espacio-temporalidad que se vive en las ciudades.

\section{El ciudadano-persona}

La noción de persona que se quiere abordar es la de un individuo donde la voz de su alma resuena sin mayor eco en las huestes de sujetos de derechos sin mayor atención en la ciudad y lo cual, los abocaría a desarrollar tácticas y estrategias de individuación para autopreservarse, desde el uso práctico de su razón y sentido gregario, que gravita dentro de sí mismos. "El ser humano es, entonces, persona en tanto es individuo de naturaleza racional y capaz de actuar por sí mismo" (Betancur, 2010, p. 131).

Sin embargo, el proceso de formarse como persona por parte de un individuo, no es fácil, pues depende de la disponibilidad de recursos, espacios y prácticas socioculturales que favorezcan su desarrollo, pero no eliminen, parafraseando a Betancur (2010, p. 134), su autonomía y su sensibilidad como sujeto, dentro de las coordenadas sociales y culturales donde le ha correspondido vivir, dada la urgencia de la ciudad, por generar equilibrios sociales ante una multitud de sujetos diversos, que buscan escapar a las marcas de la dominación y emergencia de unas identidades circunstanciales y poco deliberativas. 
Cada ser humano es un individuo, es decir, un fragmento de un espacio, una parte de ese universo, un punto singular en la inmensa red de fuerzas e influencias cósmicas, étnicas e históricas a cuyas leyes está sujeto; y al mismo tiempo es una persona, es decir, un universo de naturaleza espiritual dotado de la libertad de elección y que constituye un todo independiente frente al mundo (Choza, 1993, p. 424).

\section{La administración de la vida}

Ahora bien, intentar elaborar los argumentos de nuestra segunda posición, a saber, la del carácter intervencionista del Estado en las dimensiones público-privadas de los seres humanos, implica analizar las características mismas del Estado en cuanto actor político. Este sigue siendo entendido como el portador de la suprema autoridad dentro de un determinado territorio y en referencia a los habitantes de ese territorio, lo cual da pistas frente a que, "[...] para la definición del poder político el uso de la fuerza física es la condición necesaria, pero no es la condición suficiente" (Bobbio, 1994, p. 108). Pues en el centro de tal discusión, se ubica la pregunta sobre quién tiene el uso exclusivo de ese derecho/poder.

Un poder, que históricamente ha permitido estructurar a la sociedad mediante una dinámica de cambio en la dirección de los territorios, pero también en las representaciones y esquemas mentales que tienen los sujetos de su devenir en la historia.

Por lo que no resulta extraño que:

La pacificación interior de la persona, el hecho de que a la mayoría de nosotros no se le ocurra iniciar una pelea aunque estemos muy enfadados, de que toda la estructura de nuestra personalidad esté orientada hacia la pacificación, tiene que ver en gran parte con los efectos de la estructura estatal de la sociedad. Toda la estructura de nuestra personalidad está vertebrada por esta, y experimentamos cierto reparo o repugnancia, o cuando menos aversión, ante el uso de la violencia, y este proceso se ha ido desarrollando a lo largo de los años. [...] La pacificación se ha interiorizado, al igual que lo ha hecho la estructura de nuestra personalidad (Elías, 1994, p. 143).

Se hace mención de estas situaciones toda vez que ratifican la validez de la tesis hobbesiana de que es a la civilización y no al estado de naturaleza hacia donde debe orientarse el hombre, si desea vivir consigo mismo y vivir con los demás. Esto, dada la necesidad de supervivencia, que hace imperativo generar pactos entre los individuos para regular la vida en sociedad.

No obstante, dichos pactos operan en dos sentidos, uno externo que se visualiza en la cultura y otro interno, con la adopción de pautas de comportamiento, actitudes y valores por parte del individuo. Dimensiones, que revelan la tensión permanente a la que se enfrentan en el espacio citadino, por ejemplo, las minorías sexuales y otros colectivos sociales, dada la visibilidad de sus prácticas y sus modos de habitar la ciudad, frente a los pactos y arreglos sociales que esta misma crea y establece para forjar sujetos útiles. ¿Y esto para qué? Si como anuncia García Márquez en el Cataclismo de Damocles (1986):

Un minuto después de la última explosión, más de la mitad de los seres humanos habrá muerto, el polvo y el humo de los continentes en llamas derrotarán a la luz solar, y las tinieblas absolutas volverán a reinar en el mundo. Un invierno de lluvias anaranjadas y huracanes helados invertirá el tiempo de los océanos y volteará el curso de los ríos, cuyos peces habrán muerto de sed en las aguas ardientes, y cuyos pájaros no encontrarán el cielo. Las nieves perpetuas cubrirán el desierto del Sáhara, la vasta Amazonia desaparecerá de la faz del planeta destruida por el granizo, y la era del rock y de los corazones transplantados estaría de regreso a su infancia glacial. Los pocos seres humanos que sobrevivan el primer espanto, y los que hubieran tenido el privilegio de un refugio a las tres de la tarde del lunes aciago de la catástrofe magna, sólo habrán salvado la vida para morir después por el horror de sus recuerdos. La Creación habrá terminado. En el caos final de la humedad y las noches eternas, el único vestigio de lo que fue la vida serán las cucarachas (p. 1).

Hablo de reflexiones pasadas, no desligadas del presente, pero tampoco tan distantes del futuro que le depara a los individuos y a su hábitat, para elaborar la defensa de nuestra tercera tesis, consistente en la modelación subjetiva y corporal que realiza el mercado sobre el sujeto. En otras palabras, de la pérdida de su identidad y felicidad por la angustia de lo efímero, de lo ampliamente dispuesto y socialmente válido, que encierra y dinamiza ese espacio de intercambio gestado en la ciudad; independientemente de si esta tiene una vocación más urbana que rural o viceversa. 
Mientras el hombre no viva según su verdadera naturaleza no podrá liberarse del estado de insatisfacción, de desgarramiento y de desdicha interior. La pólis es la que asegura la mediación entre el individuo y el cosmos; el orden de la ciudad corresponde al orden del mundo, estriba en los mismos principios de organización jerárquica (Margot, 2007, p. 60).

El principio al que se refiere Margot no es otro que el bien común, pero sin renunciar al bienestar de cada individuo. La producción y el consumo son la estrella que guía la vida actual.

En el reino del consumo el ciudadano es rey. Una realeza democrática: igualdad ante el consumo (1), fraternidad en el consumo (2), libertad según el consumo (3). La dictadura de lo consumible ha borrado las barreras de la sangre, del linaje y de la raza; habría que alegrarse sin reservas, si el consumo no hubiera prohibido mediante la lógica de las cosas toda diferenciación cualitativa, para no tolerar entre los valores y los hombres más que diferencias de cantidad (Vaneigem, 1977, pp. 67-70, citado por Margot, 2007, p. 68).

El mercado en tanto expresión cultural y económica surgida en la ciudad ha generado exclusiones sociales (mujeres, niños, discapacitados) y la eliminación de cuestiones fundamentales para vivir en comunidad. A tal punto, que parece obvio su carácter alienante para aquellos sujetos que se atreven a sumergirse en sus aguas y descansar en sus playas atiborradas de artilugios. Pues el mercado no reposa en el regazo de la solidaridad, como producto del desarrollo humano en sociedad, sino de la competencia y el egoísmo natural que caracteriza a los animales racionales.

¿Cómo superar esto? La respuesta viene desde la propuesta del "Buen vivir", elaborada por los pueblos indígenas andinos y que consiste en superar la incapacidad del capitalismo de pensar de otra manera, sin autodestruirse. Es decir, considerando que el logro de una vida plena, se da bajo una relación de complementariedad entre sujetos humanos integrados al paisaje natural y no solamente en la adquisición de bienes y servicios, como satisfactores inmediatos de la práctica vital, pero en detrimento de la naturaleza.

Desde nuestra perspectiva, la presente crisis es una crisis general del sistema capitalista neoliberal que se expresa como una severa depresión económica mundial, que a su vez, significa una declinación de la estrategia de reestructuración y expansión neoliberal basada en la superexplotación del trabajo inmediato, la depredación ambiental y la financiarización de la economía mundial; pero que, asimismo, se trata de una compleja crisis civilizatoria con rostro multidimensional que expone los límites de la valorización del capital por cuanto atenta en contra de los fundamentos de la riqueza: El ser humano y la naturaleza, y porque pone en predicamento el sistema de vida en la Tierra, es decir el metabolismo social (Márquez, 2009, p. 193).

\section{Espacios deshumanizantes y nuevas perspectivas}

Por eso, afirmar que el mercado es la expresión no uniforme e inacabada de la capacidad civilizatoria en la ciudad, implica de un lado advertir, que ella se resume en la eliminación de las resistencias surgidas desde la solidaridad y cooperación entre agentes legítimos, pero carentes de las condiciones y relaciones que dicho espacio transaccional requiere (propiedad privada, espacio físico, unidad de medida, división del trabajo, excedentes producidos) para su expansión. Además, de dejar en claro que su participación en la constitución de sujetos y subjetividades se logra mediante el auxilio de las ciencias comportamentales, la publicidad y los medios de comunicación, como eslabones de una cadena que parece jamás romperse.

Dentro de las disparidades ocasionadas por el mercado en las economías nacionales, es posible observar, que dentro de un mismo Estado, se presentan amplias brechas de desigualdad entre sus diferentes componentes territoriales, tanto así que:

Lo que se encuentra una y otra vez en estas "grandes" ciudades es un relato (y una imagen-vivencia) común de la pobreza: ésta se expresa de maneras diferenciales (según sean favelas, villas, asentamientos, ranchos, barriada, etc.) pero todas remiten en conjunto al paquete prometedor de un "Progreso" que siempre está por llegar y que, en su "mientras tanto", sólo materializa de manera homogénea las desigualdades socio-económicas producto del sistema capitalista neo-colonial (Scribano, 2007a, 2007b).

¿Para qué alimentar una utopía (progreso), sino existe la voluntad política y el civismo necesario para reclamarla, o al menos pretender construirla desde 
cosmovisiones ancestrales como el "vivir bien y buen vivir"? Expresiones que superan las urgencias y los discursos del "todo vale" en que se desenvuelve la vida humana en la ciudad, pero que al mismo tiempo, dejan entrever la urgente necesidad por restaurar la armonía perdida entre los seres humanos y de estos con la naturaleza.

Como forma alternativa de desarrollo, el "vivir bien y el buen vivir" se halla a la fecha en el centro del debate público en algunos países de América Latina y con una amplia tradición constitucionalista (Ecuador, Bolivia); tanto por su carácter holístico y conciliador (benéfico y no rivalizante), como por su postura irrestricta a un crecimiento económico que no satisfaga las necesidades y sí genere formas de dominación externas y no contextualizadas, basadas en el saber disciplinar que posee verbigracia la ciencia económica y por extensión las ciencias políticas y administrativas.

En palabras de Prada (2011):

El vivir bien (suma qamaña, en aymara) y el buen vivir (sumak kawsay, en kichwa) son cosmovisiones de los pueblos indígenas andinos, que han tratado de ser actualizados por intelectuales indígenas y mestizos como una alternativa al desarrollo, y que nacen justamente de la imposibilidad de traducir a las lenguas autóctonas ideas como las de progreso y desarrollo (p. 227).

Términos, usados en la tradición occidental para describir las dinámicas que genera la actividad económica viabilizada por la política, pero no desde una perspectiva revisionista y crítica como sí lo hace el nobel indio de economía Amaytra Sen (2000), cuando declara que:

El fin del desarrollo es aumentar las oportunidades de las personas o, en otras palabras, su libertad. Por tanto, el crecimiento no debe ser erigido como el objetivo último, sino debe comprenderse como un medio para eliminar las distintas constricciones o "faltas de libertad" (p. 16-19).

Y quién, pese a sus buenas intenciones, termina alinderado a un discurso evolutivo, antropocéntrico y de utilidad que se le otorga a la naturaleza.

Olvidando que la naturaleza tiene un valor en sí misma, independientemente del carácter instrumental o utilitario que pretendan asignarle los seres humanos. Pues en últimas, ella es quién nos contiene y determina. Razón por la cual, se hace necesario:
[...] abandonar la perspectiva instrumental y utilitaria que ha guiado las relaciones entre seres humanos y naturaleza, para comprender que la naturaleza tiene un valor intrínseco independiente de las valoraciones subjetivas que puedan asignarle los seres humanos con arreglo a sus intereses o necesidades (Gudynas, 2011, p. 3).

De esta comprensión de la naturaleza, se desprende un nuevo enfoque frente al abordaje de la realidad de nuestro tiempo, el cual implica, analizar la relación sociedad-biosfera. Esta última es el posibilitador de múltiples proyectos de vida, entre esos, los nuestros. Razón por la cual habría que preservarla. Aun cuando existen necesidades básicas que suplir para garantizar el desarrollo de la vida en la tierra, también es cierto que estas mismas necesidades son construcciones sociohistóricas, que dependiendo de la disponibilidad de recursos, pero también del rol que cumpla el Estado, podrían ser transformadas para no afectarla. Ya habría que ver cuál sería el mecanismo para lograr esto - diálogo, referendos, entre otros-.

Si algo nos han enseñado nuestras culturas indígenas, a lo largo de estos últimos 500 años de historia colonizadora es su capacidad de cohabitar con otras culturas y mantener canales abiertos que permitan generar consensos frente situaciones problema, que son comunes a ambas partes, y que dada esa misma apertura solicita trabajar unidos (unuma), para superar las resistencias que pudieran presentarse.

Aunque, "el discurso pachamámico nos ofrece una catarata de palabras en aymara, pronunciadas con tono enigmático, y una cándida lectura de la crisis del capitalismo y de la civilización occidental" (Stefanoni, 2011, p. 261). También es cierto que ese mismo discurso parece obviar la responsabilidad de algunas comunidades étnicas sumadas al resto del conjunto social, frente al uso de los recursos naturales y la aniquilación de otros colectivos humanos por ejemplo; pero que hoy bajo las expresiones "vivir bien o buen vivir" pretenden reconstruirse nostálgicamente dentro de un paisaje que fue y ya no está.

La dimensión socioeconómica del buen vivir se expresa, en últimas, en un ideal de la economía orientado a la satisfacción de necesidades básicas y a los valores de reciprocidad y complementariedad, que deben prevalecer dentro de los procesos de producción, comercialización y trabajo cooperativo, que impone el mercado e incluso combinándolos con criterios de justicia social distributiva, para evitar 
causar mayores daños a los ya ocasionados sobre el ambiente y las personas.

Dada nuestra calidad de ciudadanos, la tarea que nos corresponde hoy, está en activar nuestra capacidad de agencia para construir redes de apoyo y trabajo colaborativo, con miras a no sucumbir al paradigma capitalista de corte neoliberal en que se enmarcan nuestras vidas, como producto de la civilización occidental.

\section{A manera de colofón}

De acuerdo con lo consignado en el texto, es posible afirmar que la vida humana que se desarrolla en la ciudad, no es más que la teatralización de un proceso civilizatorio que en su momento estuvo colmado de buenas intenciones y promesas de gloria, pero que hoy, constituye la causa de un buen número de situaciones negativas que afectan a sus agregados y visibiliza lo que ocurre en sus contornos. Independientemente de si se tiene o no memoria histórica.

Esto toda vez que la ciudad moderna configura un espacio desde donde producir, relacionarse y vivir en el anonimato si se quiere, pero en cuya dinámica, lo que hay de fondo es una continua tensión entre los diferentes individuos que la habitan, frente a las demarcaciones socioespaciales, de tiempo y consumo, que se le imprimen a las personas y ciudadanos de dicho espacio público.

Por tal motivo, considerar a la ciudad una máscara civilizatoria, en razón de que oculta la dualidad ensueño urbano-utopía social, no solo sea el pretexto para reflexionar sobre ella, sino para generar la formación de sentido en aquellos que viven en ella y también en quienes no. La experiencia de vivir en la ciudad, no solo es racional y económica, sino también sensorial y muy emotiva.

\section{Referencias}

Betancur, M. (2010). Persona y máscara. Revista Praxis Filosófica, 30, 127-143. Recuperado de http://praxis. univalle.edu.co/numeros/n30/PraxisFilosofica30_ MCBetancur.pdf

Bobbio, N. (1994). Estado, gobierno y sociedad. México: Fondo de Cultura Económica.
Castells, M. (1976). La cuestión urbana. México: Siglo xxi Editores.

Choza, J. (1993) Introducción a la filosofía del hombre. Navarra: Eunsa.

De Sousa-Santos, B. (2012). De la mano de Alicia: lo social y político en la postmodernidad. Bogotá: Siglo del Hombre Editores-Uniandes.

Elías, N. (1994). Civilización y violencia. Revista REIS, 65, 141-151. http://dx.doi.org/10.2307/40183672

García, G. (1986). El cataclismo de Damocles. San José: Editorial Universidad para la Paz.

Gennari, M. (1998). Semántica de la ciudad y educación. Pedagogía de la ciudad. (A. Martínez, Trad.). Barcelona: Herder.

Gudynas, E. (2011). Buen vivir: germinando alternativas al desarrollo. América Latina en Movimiento. Recuperado de http://www.alainet.org/es/active/48052

Margot, J. (2007). La felicidad. Revista Praxis Filosófica, 25, 55-79. Recuperado de http://www.scielo.org.co/pdf/ pafi/n25/n25a04.pdf

Márquez, H. (2009). Diez rostros de la crisis civilizatoria del sistema capitalista mundial. Problemas del desarrollo. Revista Latinoamericana de Economía, 159, 191-210. Recuperado de http://www.redalyc.org/ pdf/118/11820103010.pdf

Prada, R. (2011). El buen vivir como modelo de Estado y modelo económico. En M. Lang y D. Mokrani (Eds.), Más allá del desarrollo (pp. 227-257). Quito: Abya-Yala, Fundación Rosa Luxemburgo.

Scribano, A. (2007a). La Sociedad hecha callo: conflictividad, dolor social y regulación de las sensaciones. En A. Scribano (Comp.), Mapeando interiores. Cuerpo, conflicto y sensaciones. Córdoba: Jorge Sarmiento Editor.

Scribano, A. (Comp.). (2007b). Policromía corporal. Cuerpos, grafías y sociedad. UNC-CEA/CONICET y Universidad de Guadalajara. Córdoba: Universitas.

Sen, A. (2000). Desarrollo y libertad. Barcelona: Planeta.

Stefanoni, P. (2011). ¿Adónde nos lleva el pachamamismo? Tabula Rasa, 15, 255-273. Recuperado de http://www. revistatabularasa.org/numero-15/12stefanoni.pdf

Vaneigem, R. (1977). Tratado del saber vivir para uso de las jóvenes generaciones. Barcelona: Anagrama. 